\title{
Interventional Study Protocol Version Accepts Healthy Volunteers Indicator
}

National Cancer Institute

\section{Source}

National Cancer Institute. Interventional Study Protocol Version Accepts Healthy

Volunteers Indicator. NCI Thesaurus. Code C93850.

Specifies whether persons who have not had the condition(s) being studied or otherwise related conditions or symptoms, as specified in the eligibility requirements, may participate in the study. 